\title{
Design and Optimization of the Power Management Strategy of an Electric Drive Tracked Vehicle
}

\author{
Qunzhang Tu, Xiaochen Zhang, Ming Pan, Chengming Jiang, and Jinhong Xue \\ College of Field Engineering, PLA University of Science and Technology, Nanjing 210007, China \\ Correspondence should be addressed to Chengming Jiang; jcmsweet@163.com
}

Received 2 April 2016; Revised 8 August 2016; Accepted 16 August 2016

Academic Editor: Yan-Jun Liu

Copyright (C) 2016 Qunzhang Tu et al. This is an open access article distributed under the Creative Commons Attribution License, which permits unrestricted use, distribution, and reproduction in any medium, provided the original work is properly cited.

This article studies the power management control strategy of electric drive system and, in particular, improves the fuel economy for electric drive tracked vehicles. Combined with theoretical analysis and experimental data, real-time control oriented models of electric drive system are established. Taking into account the workloads of engine and the SOC (state of charge) of battery, a fuzzy logic based power management control strategy is proposed. In order to achieve a further improvement in fuel economic, a DEHPSO algorithm (differential evolution based hybrid particle swarm optimization) is adopted to optimize the membership functions of fuzzy controller. Finally, to verify the validity of control strategy, a HILS (hardware-in-the-loop simulation) platform is built based on ASPACE and related experiments are carried out. The results indicate that the proposed strategy obtained good effects on power management, which achieves high working efficiency and power output capacity. Optimized by DEHPSO algorithm, fuel consumption of the system is decreased by $4.88 \%$ and the fuel economy is obviously improved, which will offer an effective way to improve integrated performance of electric drive tracked vehicles.

\section{Introduction}

Depending on its outstanding performance in power supply, energy saving, noise reduction, and environmental protection, the electric drive technology has been extensively applied in high speed railway, hybrid vehicle, and military nowadays. In the research of tracked vehicle technology, AETV (All Electric Tracked Vehicle) has become the main direction around the world, which has advantages of high output capacity, low emissions, and sustainability. A typical structure of tracked vehicle electric drive system is shown in Figure 1.

The main power sources of the system are enginegenerator set (IGPU system) and battery. In the running process of system, chemical energy is converted into mechanical energy and transferred to generator through the gearbox; the bilateral motors are driven by energy from generator and battery.

Because of dramatic changes in external load, the system often needs to undertake huge amounts of electric power. Therefore, how to manage and distribute the power supplying task reasonably has become a hot issue. In [1] a ruled based power management strategy is proposed, taking into account the state of charge of battery. In [2] a power following strategy is proposed, which forces output power of engine to follow the load requirements of vehicle. Global optimization strategy based on genetic algorithm (GA) and dynamic programming (DP) are presented in [3] and [4], respectively, which rely on given driving cycles and have huge amounts of computations. In $[5,6]$ an equivalent consumption minimization strategy is introduced which achieves the optimal management of power sources by establishing the conversion relationship between fuel and electricity. In [7] a control algorithm based on threelayer BP neural networks is presented, which is effective but hard to be achieved.

The electric drive system of the tracked vehicle is complex nonlinear system, which is difficult to be accurately described and modeled by mathematical equations. In order to improve the feasibility and robustness of the control strategy, fuzzy control theory has been adopted for power management strategy design. Fuzzy theory was proposed by Zadeh in 1965 [8], and the basic idea of fuzzy control strategy is to formulate 


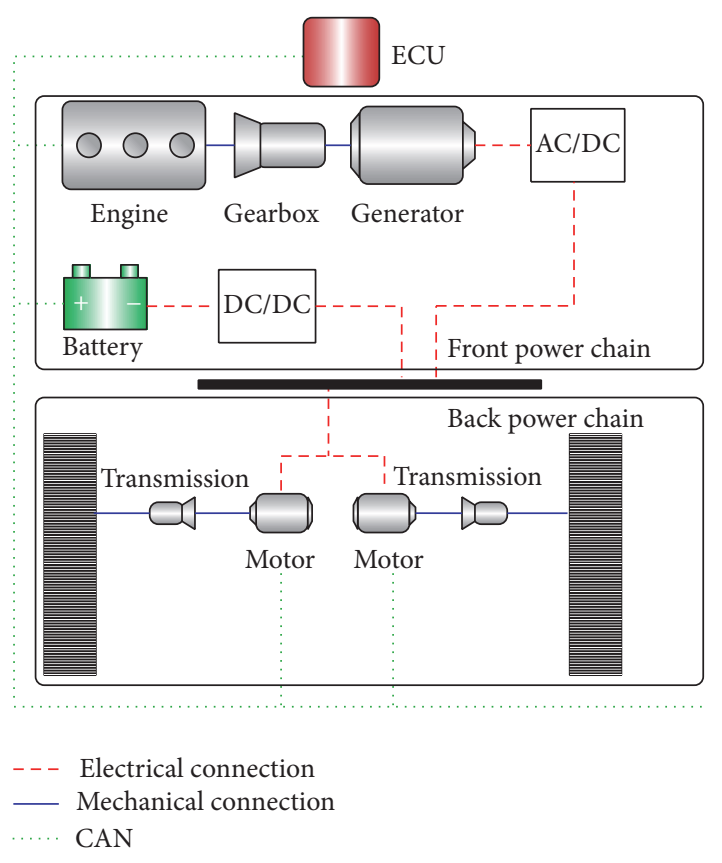

FIgURE 1: Structure of tracked vehicle electric drive system.

a collection of fuzzy IF-THEN rules from human knowledge and reasoning, which offers a qualitative description of controlled system. In [9-14] the adaptive fuzzy controller design is researched for nonlinear systems, and the effectiveness and applicability of the proposed approach has been demonstrated. In $[15,16]$ fuzzy neural network based adaptive control algorithm is proposed for a class of nonlinear systems, and online computation load is greatly reduced. In [17] an adaptive neural controller for nonlinear multiple-input multiple-output systems with unknown hysteresis inputs is researched, and the stability of the close loop system has been verified. In [18-21] fuzzy logic based power management strategies are studied which have good robustness and easy to realize, but membership functions of fuzzy controller are usually determined by experts' experience and optimality of the strategy cannot be ensured.

To find an efficient and simple way to manage the power source of tracked vehicle electric drive system, this paper presents a fuzzy based power management strategy. To ensure the optimality of the strategy, a differential evolution based hybrid particle swarm optimization algorithm is adopted to optimize the fuzzy controller. Finally, the proposed strategy is verified by a driver-controller based HILS (hardware-inthe-loop simulation) platform.

\section{Modeling of the Electric Drive System}

2.1. IGPU System. The IGPU system, which consists of an electronic governor diesel engine and a permanent magnet synchronous motor (PMSM), is the main power source of the electric drive system. Because of the torque and speed coupling of the engine and generator, this paper considers them as a whole when modeling. The load torque of the engine $\left(T_{e}\right)$ is numeric equivalent to electromagnetic torque

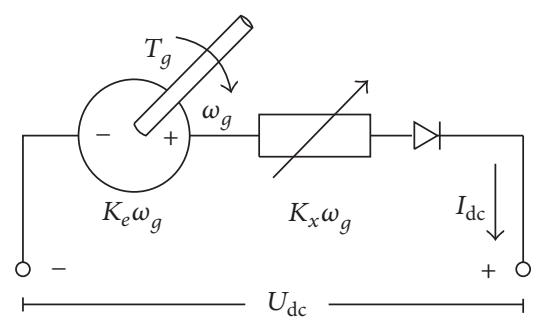

FIGURE 2: Equivalent circuit of engine-generator set.

of the generator $\left(T_{g}\right)$. The following expressions can be obtained by speed and torque balance:

$$
\begin{aligned}
\frac{T_{e}}{i_{k}}-T_{g} & =0.1047 \cdot \frac{\mathrm{d} n_{g}}{\mathrm{~d} t} \cdot\left(\frac{J_{e}}{i_{k}^{2}}+J_{g}\right), \\
n_{g} & =n_{e} i_{k},
\end{aligned}
$$

where $n_{e}$ is the rotational speed of the engine, $n_{g}$ is the rotational speed of the generator, $i_{k}$ is the transmission ratio of the gearbox, and $J_{e}$ and $J_{g}$ are the rotational inertia of engine and generator.

The generator is connected to the DC BUS through a three-phase bridge uncontrolled rectifier with filter capacitor $[22,23]$; the equivalent circuit of PMSM with bridge rectifier can be simplified, represented in Figure 2.

Ignore the internal resistance voltage drop and torque loss of generator, the relationship between BUS voltage $\left(U_{\mathrm{dc}}\right)$ and electromagnetic torque of generator can be expressed as follows:

$$
\begin{gathered}
U_{\mathrm{dc}}=K_{e} \omega_{g}-K_{x} \omega_{g} I_{\mathrm{dc}}, \\
T_{g}=K_{e} I_{\mathrm{dc}}-K_{x} I_{\mathrm{dc}}^{2},
\end{gathered}
$$

where $I_{\mathrm{dc}}$ is the BUS current, $K_{e} \omega_{g}$ is the electromotive force, and $K_{x} \omega_{g}$ is the equivalent resistance.

In order to calculate fuel consumption of engine, an experiment was taken and mapping characteristics of the engine were obtained. The main equipment and data processing results of the experiment are shown in Figures 3 and 4 , respectively. It can be seen from Figure 4 that the fuel consumption rate of the engine varies in a large range. Thus, the engine should be controlled to work in property point in order to improve fuel efficiency.

Given an operation point of engine $P\left(n_{e}, T_{e}\right)$, the specific fuel consumption $\left(b_{e}=f\left(n_{e}, T_{e}\right)\right)$ can be obtained by looking up the surface in Figure 4. Therefore, fuel consumption of engine $\left(V_{e}\right)$ can be expressed as follows:

$$
V_{e}=\frac{b_{e} T_{e} n_{e}}{9550 \eta_{e} \rho_{e}}
$$

where $\rho_{e}$ is the density of diesel and $\eta_{e}$ is the output efficiency of engine. To satisfy the power tracking demand of engine, a best fuel consumption based variable speed control strategy is adopted in this article [24]. Three fixed speed points (which include $n_{\mathrm{I}}=1450 \mathrm{r} / \mathrm{min}, n_{\mathrm{II}}=1750 \mathrm{r} / \mathrm{min}$, and 


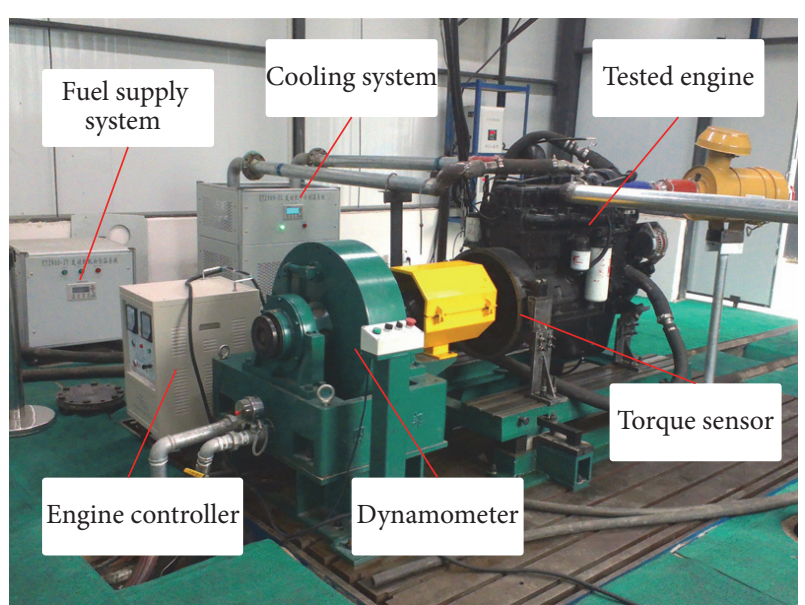

FIGURE 3: Test-bed of mapping characteristics experiment.

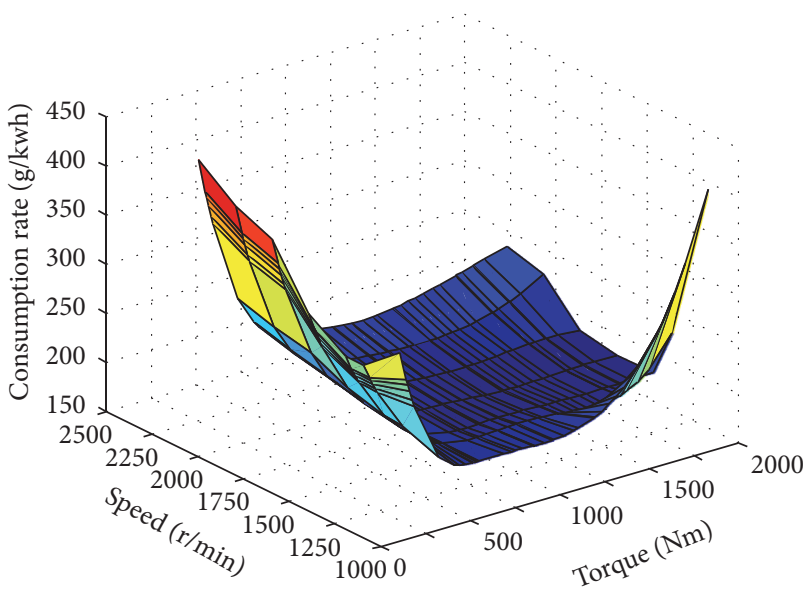

FIGURE 4: Fuel consumption surface of engine.

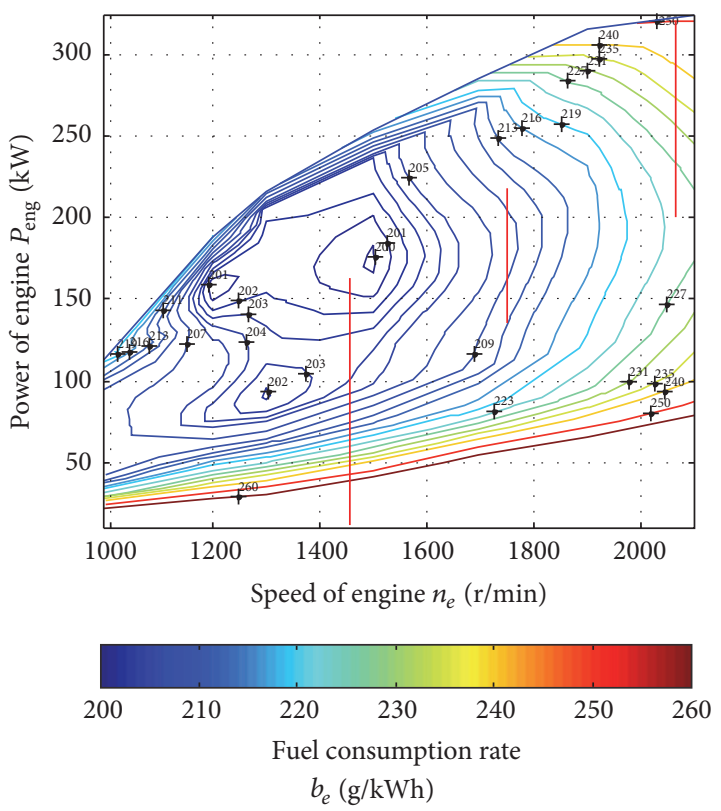

FIGURE 5: Distribution of speed points in engine MAP.
$n_{\mathrm{III}}=2150 \mathrm{r} / \mathrm{min}$ ) are set in the economical area of fuel consumption, as shown in Figure 5, and operation speed of engine is regulated between the points according to power demand of back power chain. The 3 lines in Figure 5 represent the fixed working speed of the engine, which is $1450 \mathrm{r} / \mathrm{min}$, $1750 \mathrm{r} / \mathrm{min}$, and $2150 \mathrm{r} / \mathrm{min}$ from left to the right.

Speed and torque regulation of IGPU system can be achieved by electronic governor model which consists of two PI control units, as shown in Figure 6. The outer PI unit regulates the target rotational speed $\left(\omega_{e}^{*}\right)$ according to the error between target and actual output power of engine $\left(e_{P}\right)$, while the inner one regulates the target torque $\left(T_{e}^{*}\right)$ according to the error between target and actual rotational speed of engine $\left(e_{\omega}\right)$ under the restriction of external characteristics.

The control process can be described as follows:

$$
\begin{aligned}
& \omega_{e}^{*}=K_{P} e_{P}+K_{I} \int_{t_{0}}^{t} e_{P} \mathrm{~d} t+\omega_{e}, \\
& T_{e}^{*}=\min \left\{\left(K_{P} e_{\omega}+K_{I} \int_{t_{0}}^{t} e_{\omega} \mathrm{d} t\right), T_{e \max }\left(\omega_{e}\right)\right\},
\end{aligned}
$$

where $K_{P}$ and $K_{I}$ are the control loop parameter and $T_{e \max }\left(\omega_{e}\right)$ is the maximum torque under a certain speed, which can be obtained by Figure 5 .

2.2. Driving Motor. Modeling for driving motor in this article mainly focuses on the motor's speed, torque, and efficiency characteristics and does not consider the transformation of its internal voltage and current. In order to get the output characteristics of motor, a driving motor experiment was taken and the main equipment and data processing results are shown in Figures 7 and 8, respectively.

Considering of time delay caused by response of motor controller, an additional one-order lag $(1 /(\tau s+1))$ is added before the output. The output torque of motor $\left(T_{m}\right)$ can be expressed as follows:

$$
\begin{aligned}
& T_{m} \\
& = \begin{cases}\frac{T_{\text {req }} \eta}{(\tau s+1)} & T_{b \max }\left(n_{m}\right) \leq T_{\text {req }} \leq T_{d \max }\left(n_{m}\right) \\
\frac{T_{d \max }\left(n_{m}\right) \eta}{(\tau s+1)} & T_{\text {req }}>T_{d \max }\left(n_{m}\right) \\
\frac{T_{b \max }\left(n_{m}\right) \eta}{(\tau s+1)} & T_{\text {req }}<T_{b \max }\left(n_{m}\right)\end{cases}
\end{aligned}
$$

where $T_{\text {req }}$ is the requested torque of engine, $T_{b \max }\left(n_{m}\right)$ and $T_{d \max }\left(n_{m}\right)$ are the maximum braking and driving torque of motor under speed of $n_{m}$, and $\eta$ is the output efficiency of motor, which can be obtained by Figure 8 .

2.3. Battery. Battery is an auxiliary power source of electric drive system which inputs or outputs power according to command of controller and provides information of SOC (state of charge). Based on the method of equivalent electrical circuit, the battery is simplified as an ideal voltage source and charge/discharge resistor in a series circuit, which is shown in Figure 9 [25]. 


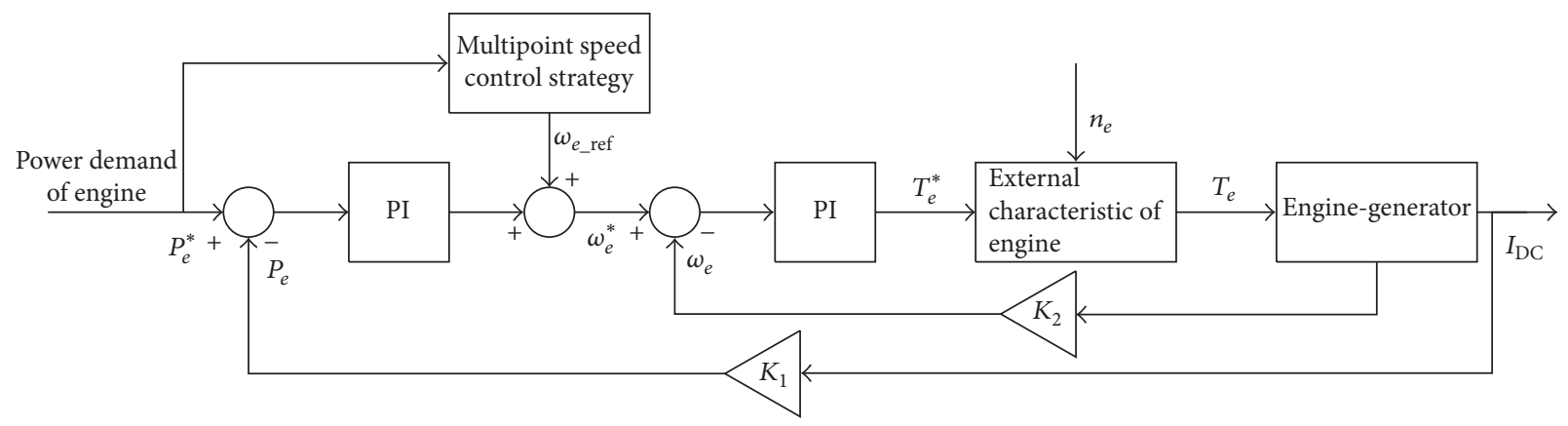

FIGURE 6: Electronic governor model of IGPU system.

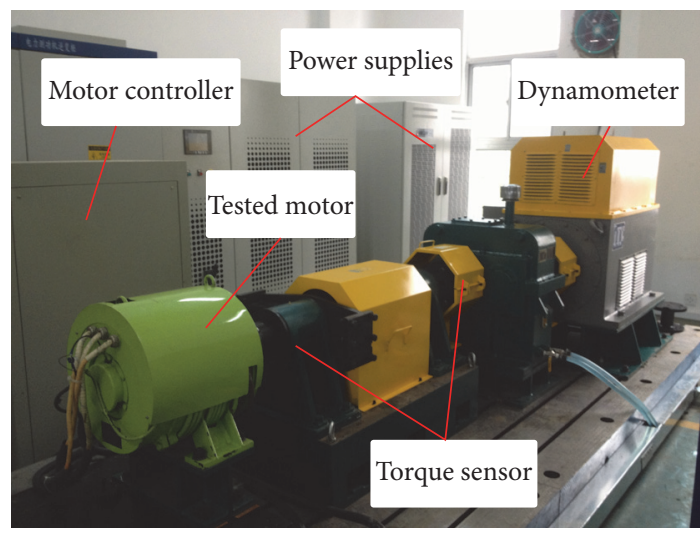

FIgURE 7: Test-bed of driving motor experiment.

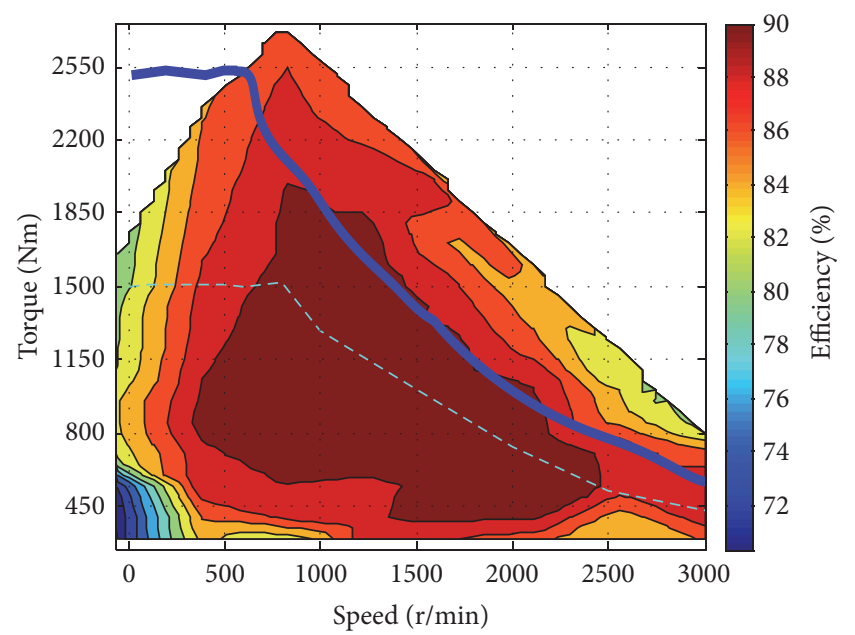

Efficiency MAP
- Peak torque
- Rated torque

FIGURE 8: Output efficiency MAP of motor.

According to the circuit, the relationship between terminal voltage and charge/discharge current can be expressed as follows:

$$
\begin{gathered}
U_{f \mathrm{bat}}=E_{\mathrm{bat}(\mathrm{SOC})}+I_{f \mathrm{bat}} R_{f s(\mathrm{SOC})} \text { discharge, } \\
U_{c \mathrm{bat}}=E_{\mathrm{bat}(\mathrm{SOC})}+I_{c \mathrm{bat}} R_{c s(\mathrm{SOC})} \quad \text { charge, }
\end{gathered}
$$

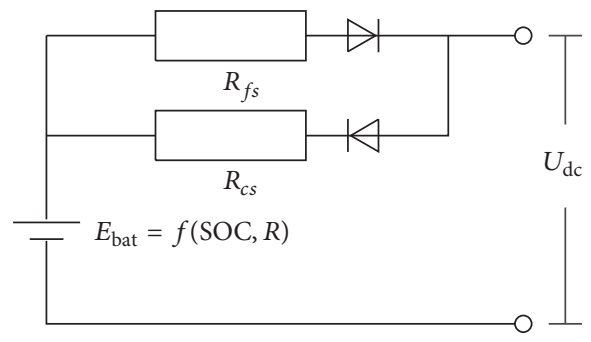

Figure 9: Equivalent electrical circuit of battery.

where $U_{c \text { bat }} / U_{f \text { bat }}$ is the terminal voltage of battery when charging/discharging, $I_{c \text { bat }} / I_{f \text { bat }}$ is the current through the resister when charging/discharging, $R_{c s(\mathrm{SOC})} / R_{f s(\mathrm{SOC})}$ is the resister of battery when charging/discharging, and $E_{\mathrm{bat}(\mathrm{SOC})}$ is the open-circuit voltage of battery.

Based on ampere hour method [26], SOC of battery at any time can be expressed as follows:

$$
\operatorname{SOC}(t)=\frac{\left(Q_{0}-\int_{0}^{t} I_{\text {bat }}(t) d t\right)}{Q_{\max }},
$$

where $Q_{0}$ and $Q_{\max }$ are the initial and maximum capacity of battery and $I_{\text {bat }}(t)$ is the output current (positive when discharging).

2.4. Dynamics Model of Tracked Vehicle. Simplified moving plane of tracked vehicles is shown in Figure 10. Dynamic equations of tracked vehicle based on equilibrium relationship can be expressed as follows:

$$
\begin{aligned}
\dot{v}_{y} & =\frac{\left(F_{1}+F_{2}-F_{r 1}-F_{r 2}\right)}{m}, \\
\dot{\omega} & =\frac{\left[0.5 B\left(F_{2}-F_{1}+F_{r 1}-F_{r 2}\right)-M_{h}\left(\mu, v_{y}, \omega\right)\right]}{I_{z}}, \\
R & =\frac{v_{y}}{\omega}, \\
n_{1,2} & =\frac{30 i_{g}\left(v_{y} \pm \omega B / 2\right)}{\pi r},
\end{aligned}
$$

where $m$ is the mass of vehicle, $r$ is the radius of driving wheel, $B$ and $L$ are the center distance and grounding length 
TABLE 1: Control rules of power management.

\begin{tabular}{|c|c|c|c|c|c|}
\hline Label & Engine-generator & Battery & Motor & Resistance & Control method \\
\hline a & Off & Discharge & $\mathrm{ON}$ & Off & $P_{\mathrm{bat}}^{*}=\min \left(P_{L}, P_{f \max }\right), P_{e}^{*}=0, P_{R}^{*}=0$ \\
\hline $\mathrm{b}$ & On & Charge & $\mathrm{ON}$ & Off & $P_{\text {bat }}^{*}=-\min \left(P_{e \max }-P_{L},\left|P_{c \max }\right|\right), P_{e}^{*}=P_{L}-P_{\text {bat }}^{*}, P_{R}^{*}=0$ \\
\hline c & On & Discharge & $\mathrm{ON}$ & On/Off & $P_{\mathrm{bat}}^{*}=P_{f \max }, P_{e}^{*}=\max \left(P_{L}-P_{\mathrm{bat}}^{*}, 0\right), P_{R}^{*}=\min \left(P_{L}-P_{\mathrm{bat}}^{*}, 0\right)$ \\
\hline $\mathrm{d}$ & On/Off & Charge & OFF & Off & $P_{\text {bat }}^{*}=-\min \left(P_{e \max }-k_{\text {bra }} P_{L},\left|P_{c \max }\right|\right), P_{e}^{*}=k_{\text {bra }} P_{L}-P_{\text {bat }}^{*}, P_{R}^{*}=0$ \\
\hline e & Off & Discharge & OFF & On & $P_{\mathrm{bat}}^{*}=P_{f \max }, P_{e}^{*}=0, P_{R}^{*}=-k_{\mathrm{bra}} P_{L}+P_{\mathrm{bat}}^{*}$ \\
\hline $\mathrm{f}$ & Off & Charge & OFF & Off & $\begin{array}{l}P_{\mathrm{bat}}^{*}=-\min \left(\left|P_{c \max }\right|,-k_{\mathrm{bra}} P_{L}\right) \\
P_{e}^{*}=0, P_{R}^{*}=0\end{array}$ \\
\hline g & On & Keep SOC at 0.7 & $\mathrm{ON}$ & Off & Manage the power source based on fuzzy rules \\
\hline
\end{tabular}

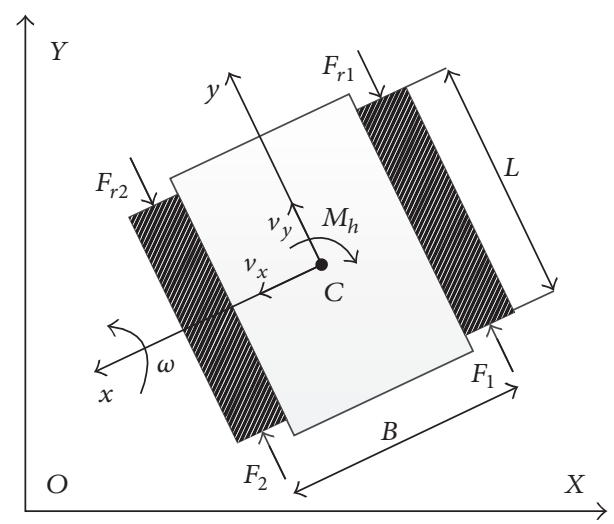

FIGURE 10: Schematic drawing of tracked vehicle.

of tracks, $F_{1,2} / F_{r 1, r 2}$ is the traction force/rolling resistance of inner and outer side of tracks, $I_{z}$ is rotary inertia of vehicle, $v_{x, y}$ is the horizontal and vertical speed, $\omega$ is the steering angular velocity, $n_{1,2}$ is rotational speed of bilateral driving wheel, $i_{g}$ is the gear ratio of transmission $\left(n_{m}=i_{g} n_{1,2}\right), M_{h}$ is the steering resisting moment related to steering resistance coefficient $(\mu)$, and $M_{h}=\mu L G / 4$ when $\omega$ is not zero.

\section{Design and Optimization of Power Management Strategy}

Because of the limited output capacity of battery, IGPU is chosen to be major power source of system, which undertakes the task of steady power output. While battery is used as an auxiliary power source and provides a timely power supplement when huge power is requested. In addition, there is a rational working range for both IGPU and battery. The IGPU has less fuel consumption in an economical area and battery has higher working efficiency when SOC is about 0.7. Therefore, in order to ensure the power supplying tasks are reasonably assigned and to keep the power source working in the best state, a power management control strategy is designed and flowchart of the strategy is shown in Figure 11.

Working conditions of electric drive system are divided into electric and hybrid modes, and hybrid mode can be further divided into driving and braking states. Load power $\left(P_{L}\right)$ and SOC are selected to be main reference variables of system, and switch of different modes can be realized according to the judgment of threshold value. When the muting switch is on, IGPU stops working and requested power is completely provided by battery. When system is in the state of hybrid mode, power demand is achieved by both IGPU and battery. For a higher working efficiency, SOC of battery should be limited in a rational range, and battery is forced to be charged/discharged when SOC is below/above the minimum/maximum value. Besides, there is also a current limiting when battery is charging or discharging, and the maximum/minimum current can be obtained by related experiments. Specific control process of the strategy can be looked up in Table 1.

where $P_{e}^{*}, P_{\text {bat }}^{*}$, and $P_{R}^{*}$ are the target power of IGPU, battery, and protective resistance, $P_{e \max }$ and $P_{f \max }$ are the maximum output power of battery when charging and discharging, and $k_{\mathrm{bra}}$ is the maximum regenerative braking coefficient.

According to the variable speed control strategy mentioned in Section 2, the working range of IGPU has been limited in an economical zone. Similarly, a double-input and single-output fuzzy control strategy is proposed to limit the value of SOC in an efficient range. The load rate $(f(P)=$ $\left.P_{L} / P_{e \max }\right)$ and SOC are chosen to be the input variables and power distribution coefficient $\left(x_{f}\right)$ is the output variable of fuzzy controller. Target power of IGPU and battery can be expressed as follows:

$$
\begin{aligned}
P_{e}^{*} & =x_{f} P_{L}, \\
P_{\text {bat }}^{*} & =\left(1-x_{f}\right) P_{L} .
\end{aligned}
$$

Fuzzy rules are defined based on the following principles:

(i) Reducing coefficient $x_{f}$ when $f(P)$ is high and the battery would output supplement power.

(ii) Raising coefficient $x_{f}$ when $f(P)$ is low to make the engine work in efficient load zone.

(iii) Keep SOC of the battery around 0.7 by adjusting $x_{f}$ to improve charge/discharge efficiency.

The membership functions of $f(P)$ and SOC of the battery are shown in Figure 12, which are defined as follows:

$f(P)$ : fuzzy set $\{S, M, B\}$, range $[0,1]$ which presents required power changes from 0 to $P_{e \max }$. 


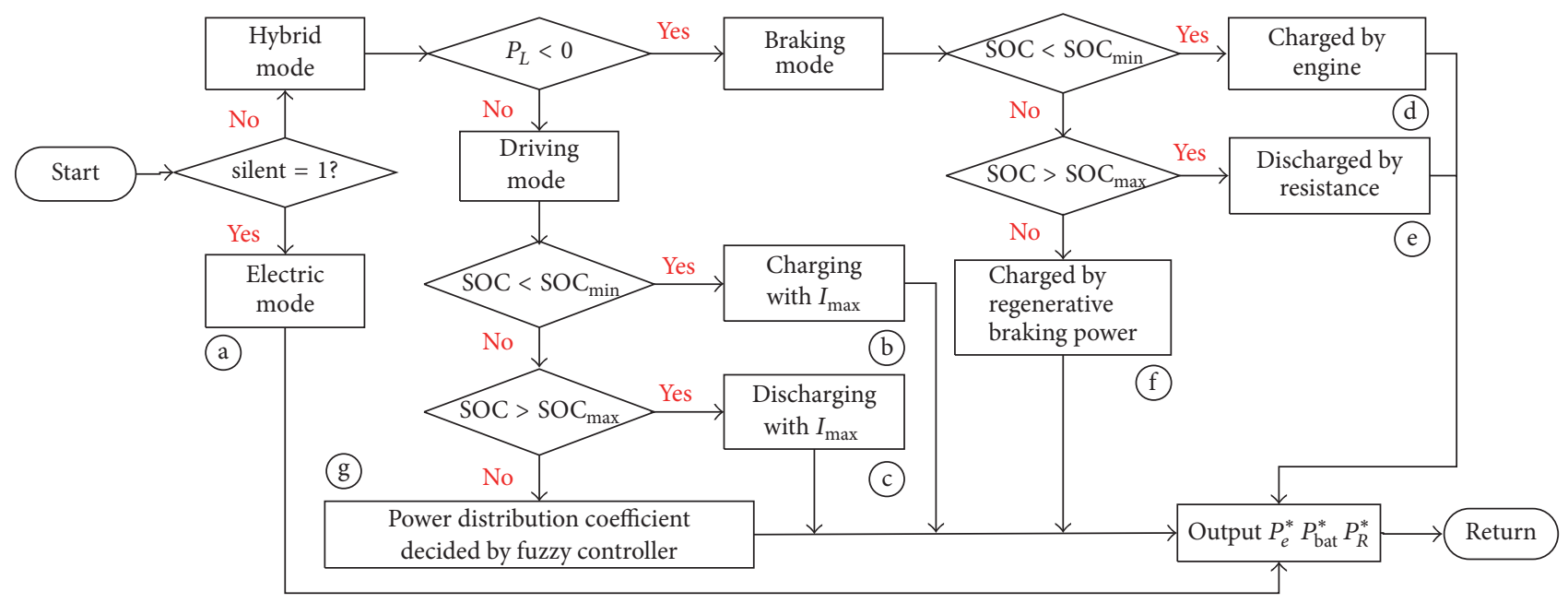

FIGURE 11: Flowchart of power management control strategy.

TABLE 2: Fuzzy rules of power management control strategy.

\begin{tabular}{lcccccc}
\hline \multirow{2}{*}{$f(P)$} & \multicolumn{5}{c}{ SOC } \\
& CS & CM & CB & FS & FM & FB \\
\hline S & VB & B & RB & M & RS & S \\
M & RS & S & VS & VS & VS & VS \\
B & VS & VS & VS & VS & VS & VS \\
\hline
\end{tabular}

SOC: fuzzy set $\{C S, C M, C B, F S, F M, F B\}$, range $[0.6$, 0.8 ] which presents SOC of the battery changes from 0.6 to 0.8 .

According to the guidelines and membership functions, using statements of "if $f(P)$ and SOC, then $x_{f}$ ", 18 rules based on Sugeno defuzzification algorithm are designed, as shown in Table 2.

Membership functions of the fuzzy controller are designed based on experiment data and experts' knowledge which will greatly affect the performance of the control strategy. In order to improve fuel efficiency of the electric drive system, a differential evolution based hybrid particle swarm optimization algorithm (DEHPSO) is proposed to optimize the membership functions of the fuzzy controller.

There are two kinds of particle swarm optimization algorithm (PSO): one is called global PSO and the other is local PSO. Expressions of global PSO are [27-29]

$$
\begin{aligned}
V g_{i D}^{k+1}= & \omega_{s} V g_{i D}^{k}+c_{1} r_{1}\left(P_{i D}^{k}-X_{i D}^{k}\right) \\
& +c_{2} r_{2}\left(G_{D}^{k}-X_{i D}^{k}\right), \\
X_{i D}^{k+1}= & X_{i D}^{k}+V g_{i D}^{k+1},
\end{aligned}
$$

where $k$ is iteration times, $i$ is the swarm number, $D$ is the dimension number, $\omega_{s}$ is the inertia factor, $c_{1,2}$ is the learning factor, and $r_{1,2}$ is the convergence factor, $V g_{i}^{k}, X_{i}^{k}, P_{i}^{k}$, and $G^{k}$ are vectors which present the velocity, position, individual extreme position, and global extreme position of the swarm, respectively. Replace $G_{D}^{k}$ with vector of local extreme position $L_{i D}^{k}$ in (10), then global PSO is changed into local PSO:

$$
\begin{aligned}
V l_{i D}^{k+1}= & \omega_{s} V l_{i D}^{k}+c_{1} r_{1}\left(P_{i D}^{k}-X_{i D}^{k}\right) \\
& +c_{2} r_{2}\left(L_{i D}^{k}-X_{i D}^{k}\right), \\
X_{i D}^{k+1}= & X_{i D}^{k}+V l_{i D}^{k+1} .
\end{aligned}
$$

The calculation speed of global PSO is faster than local PSO, but it has the premature problem. On contrast, local PSO settles the premature problem, but the convergence speed is too slow. In order to solve problems of both algorithms, a hybrid PSO is proposed by combining global PSO with local PSO which is expressed as follows:

$$
\begin{aligned}
V h_{i D}^{k+1} & =b V g_{i D}^{k+1}+(1-b) V l_{i D}^{k+1}, \\
X_{i D}^{k+1} & =X_{i D}^{k}+V h_{i D}^{k+1},
\end{aligned}
$$

where $b$ is the combination factor. In order to avoid premature problem in early time and increase convergence speed in later time of evolution period, the value of $b$ is controlled to gradually increase when iterating.

In order to increase diversity of the population and ensure that the iteration period converges to global optimal solution, the method of differential evolution (DE) is adopted in this paper for generating new particles. The optimization process can be expressed as follows:

(i) The method of judging local convergence: the variance of particles' fitness is selected as judging reference of convergence degree and the variance value of the $k$ generation can be calculated by the following equation:

$$
\left(\sigma^{2}\right)^{(k)}=\frac{1}{n_{s}}\left(\frac{f_{i}^{k}-f_{\mathrm{ave}}^{k}}{q}\right)^{2}
$$



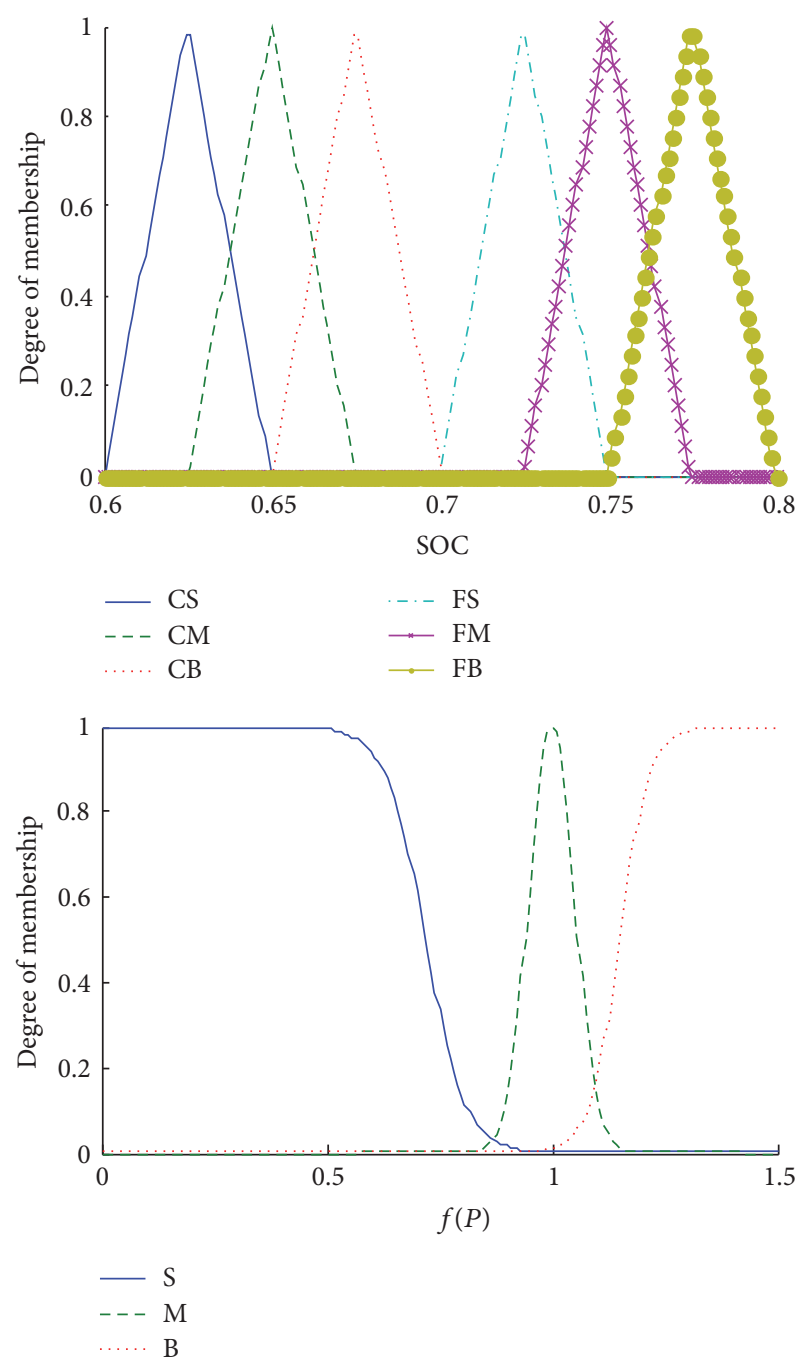

Output value of Sugeno

\begin{tabular}{cccccccc}
\hline$x_{f}$ & $\mathrm{VS}$ & $\mathrm{S}$ & $\mathrm{RS}$ & $\mathrm{M}$ & $\mathrm{RB}$ & $\mathrm{B}$ & $\mathrm{VB}$ \\
\hline Value & 0.8 & 0.85 & 0.9 & 0.95 & 1.05 & 1.1 & 1.2 \\
\hline
\end{tabular}

FIGURE 12: Membership functions of fuzzy controller.

where $n_{s}$ is the population number, $q$ is the normalized factor, $f_{i}^{k}$ is the fitness of particle $i$, and $f_{\text {ave }}^{k}$ is the average fitness of the population. The evolution process would be ended when the variance of particles' fitness $\sigma^{2}$ is less than the setting threshold value $\sigma_{s}^{2}$.

(ii) The method of mutation: DE algorithm is adopted for particle mutation and the position of the new particle is calculated by the following equation:

$$
H_{i D}^{k+1}=X_{i D}^{k}+\varsigma\left(G_{D}^{k}-X_{i D}^{k}\right)+v\left(X_{i_{1} D}^{k}-X_{i_{2} D}^{k}\right),
$$

where $v$ and $\varsigma$ are scaling factors that determine population diversity and convergence rate, respectively.

(iii) The method of crossover: select the mutational particle and its original particle as the crossover objects

and exchange their position coordinates which can be expressed by the following equations:

$$
C_{i D}^{k+1}= \begin{cases}H_{i D}^{k+1} & \text { random } \geq \text { CROSS or } D=D_{\text {rand }} \\ X_{i D}^{k} & \text { otherwise }\end{cases}
$$

where random is a random number generated by the computer, CROSS presents crossover probability, and $D_{\text {rand }}$ is a designed cross location.

(iv) The method of elimination: the newly generated particles in mutation and crossover process are compared with original particles, particles with better fitness are retained which compose a new population, and the other particles are eliminated, which can be described as follows:

$$
X_{i D}^{k+1}= \begin{cases}C_{i D}^{k+1} & \text { if } f_{\mathbf{C}_{i}^{k+1}} \text { is better than } f_{\mathbf{X}_{i}^{k}} \\ X_{i D}^{k} & \text { otherwise. }\end{cases}
$$

The optimization process by using DEHPSO algorithm is shown in Figure 13. On the basis of meeting power requirements, the optimization target of the control strategy is to minimize fuel consumption of the vehicle. As the battery SOC is expected to be stable around 0.7, changing interval of SOC is limited which is chosen as constraint condition in optimization process. Target function in the optimization process can be expressed as follows:

$$
f_{i}=m_{i} V_{e} \quad \Delta \mathrm{SOC} \in[-\varepsilon,+\varepsilon] .
$$

\section{Simulation and Results}

To guarantee the real-time high efficiency of proposed strategy, simulation experiments under different working conditions should be taken. There are two simulation methods for adoption: offline method and real-time method. Although offline method is much more simple and rapid, signals which reflect the driving intention are preset; thus, the method does not have strong randomicity. On the other hand, because strategy codes are not generated in offline simulation, the real-time efficiency of controller is hard to be verified. For reasons stated above, real-time method is adopted in this paper and the strategy is evaluated on a driver-controller based HILS platform.

Models of electric drive system built in SIMULINK are shown in Figure 14. Choosing driver input equipment and tested controller as hardware, the HILS platform is established based on dSPACE MicroAutoBox1401/1504 and the structure of which is shown in Figure 15. Models of IGPU, motors, battery, and vehicle dynamic built in host computer are compiled and downloaded into dSPACE by MATLAB/RTW interface. Model of control strategy is firstly compiled by MATLAB/Stateflow, then transcoded by TargetLink, and downloaded into the tested controller. Driving signals are collected by driver input equipment (the interpretation of which is presented in the Appendix). After processing of $\mathrm{A} / \mathrm{D}$ conversion, the controller receives the signals 


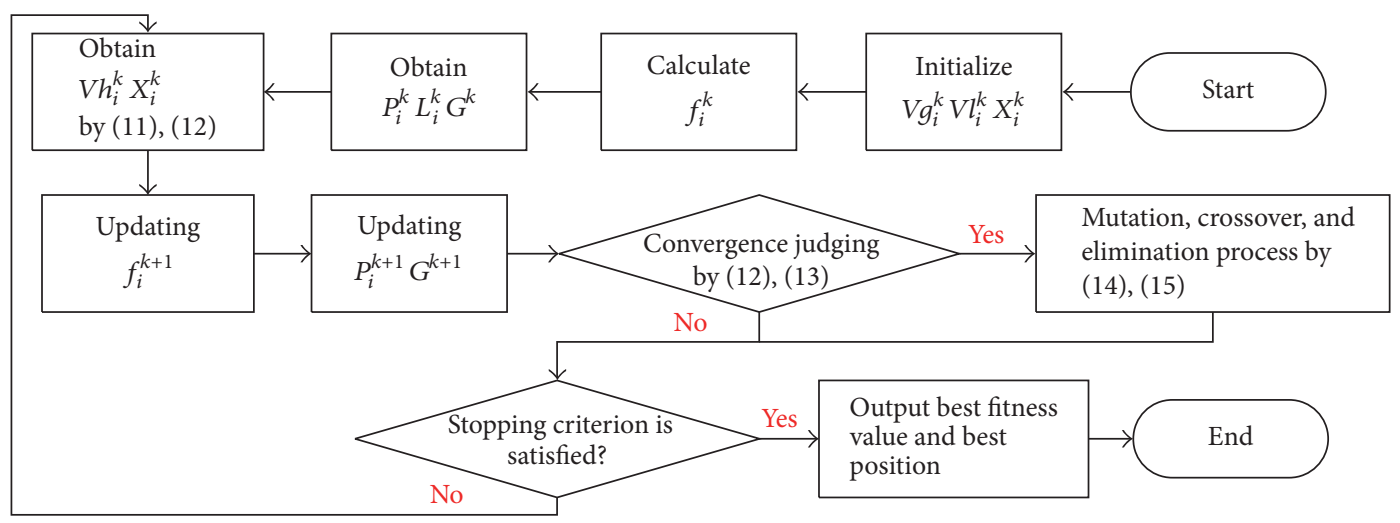

FIGURE 13: Flowchart of DEHPSO.

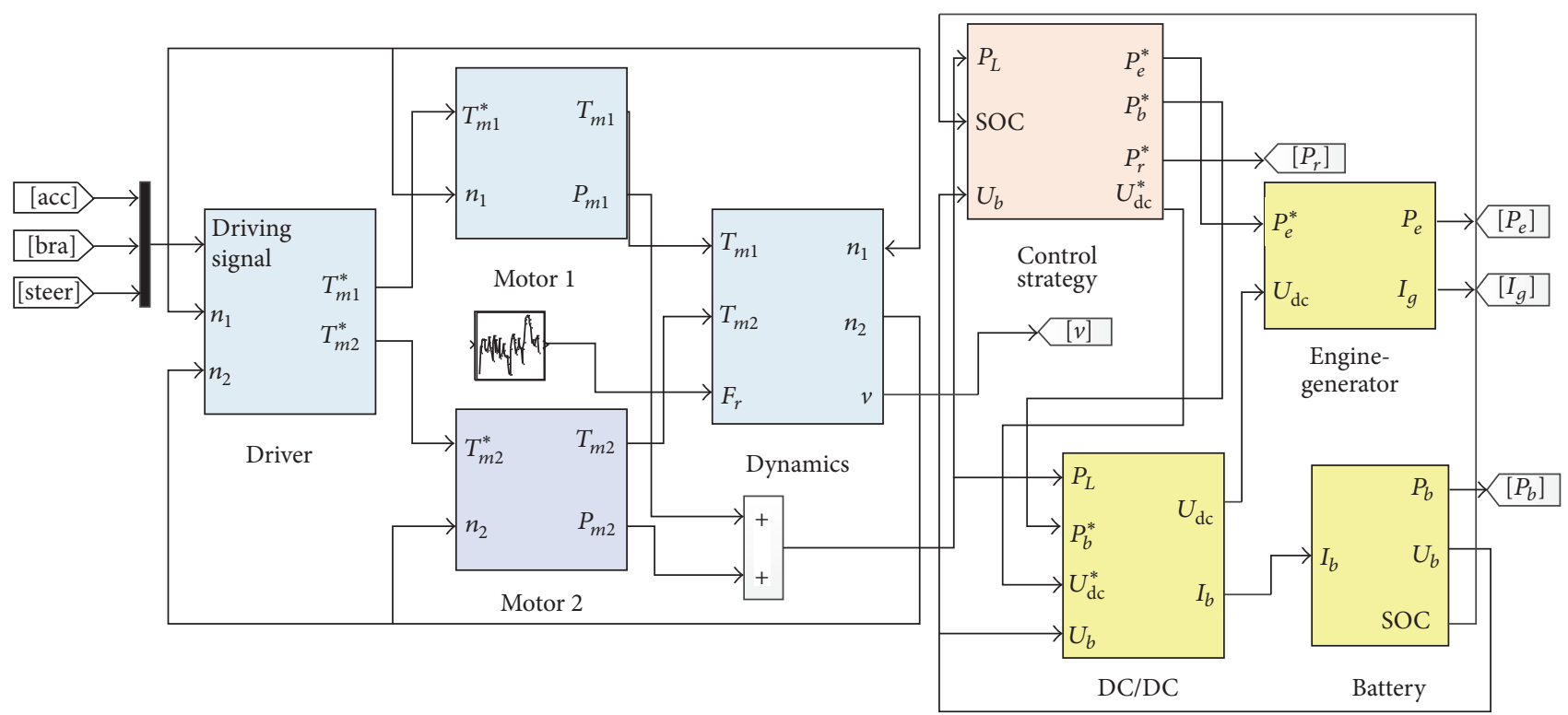

FIgURE 14: Models built in SIMULINK.

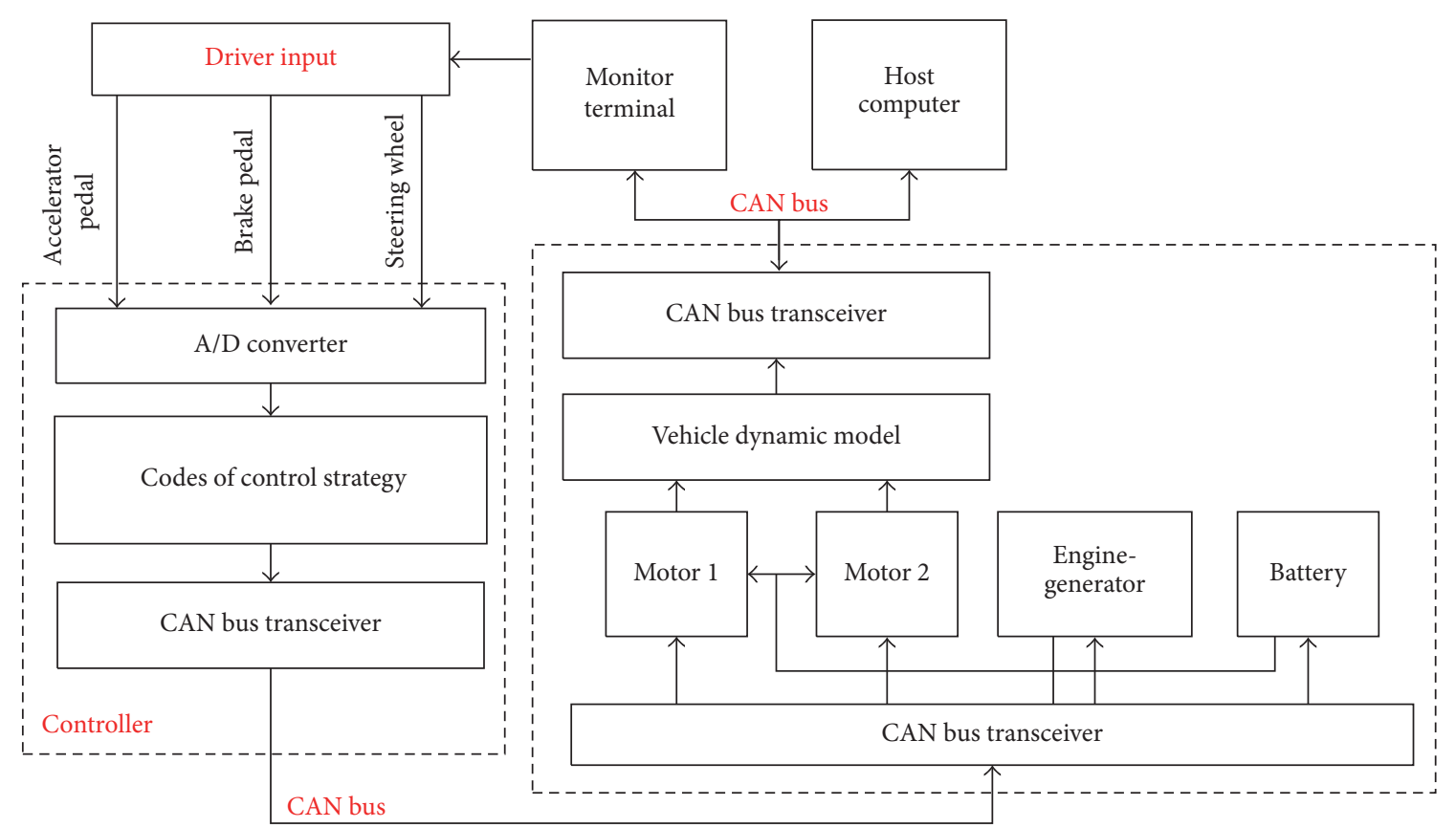

Figure 15: dSPACE based HILS platform. 


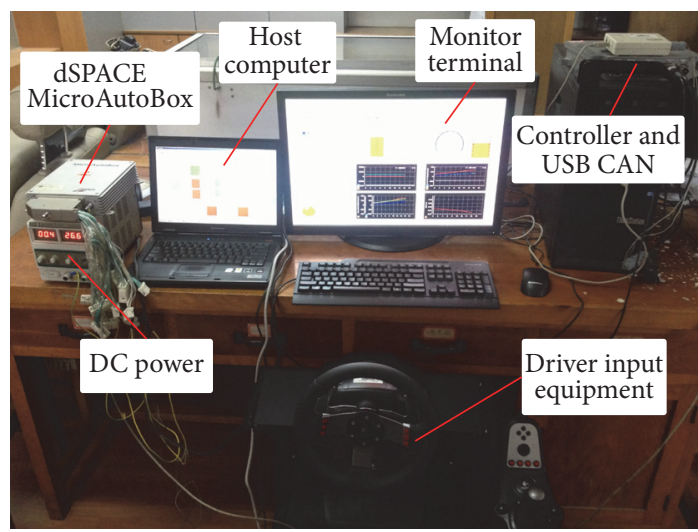

FIgURE 16: Hardware of HILS platform.

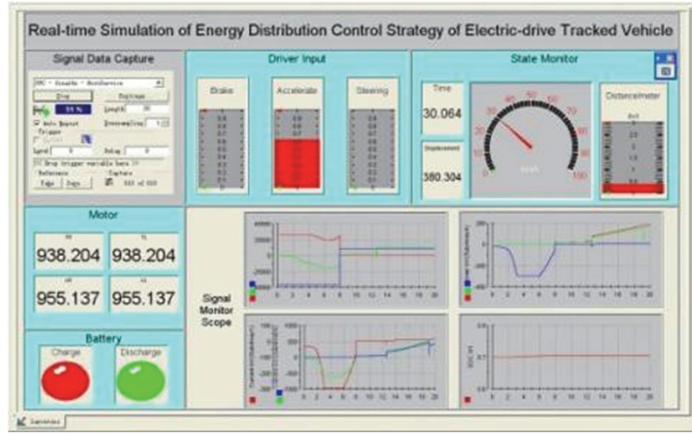

FIGURE 17: Monitor interface based on Controldesk.

TABLE 3: Parameters of the tracked vehicle used for simulation.

\begin{tabular}{lc}
\hline Parameters & Value \\
\hline$m$ & $10 \mathrm{t}$ \\
$I_{7}$ & $5 \times 10^{4} \mathrm{~kg} \cdot \mathrm{m}^{2}$ \\
$i_{g}$ & 8 \\
$\mu$ & 0.83 \\
$L$ & $2.43 \mathrm{~m}$ \\
$B$ & $1.981 \mathrm{~m}$ \\
$r$ & $0.4685 \mathrm{~m}$ \\
$J_{e}$ & $3.2 \mathrm{~kg} \cdot \mathrm{m}^{2}$ \\
$J_{g}$ & $2 \mathrm{~kg} \cdot \mathrm{m}^{2}$ \\
$i_{k}$ & 2.119 \\
$K_{e}$ & 1.446 \\
$K_{x}$ & $8.765 \times 10^{-4}$ \\
$\rho_{e}$ & $0.83 \mathrm{t} / \mathrm{m}^{3}$ \\
$k_{\text {bra }}$ & 0.26 \\
$\omega_{s}$ & 0.6 \\
$n_{s}$ & $\varsigma$ \\
$v$ & 100 \\
CROSS & 0.4 \\
$\sigma_{s}^{2}$ & 0.6 \\
$\varepsilon$ & 0.8 \\
\hline
\end{tabular}
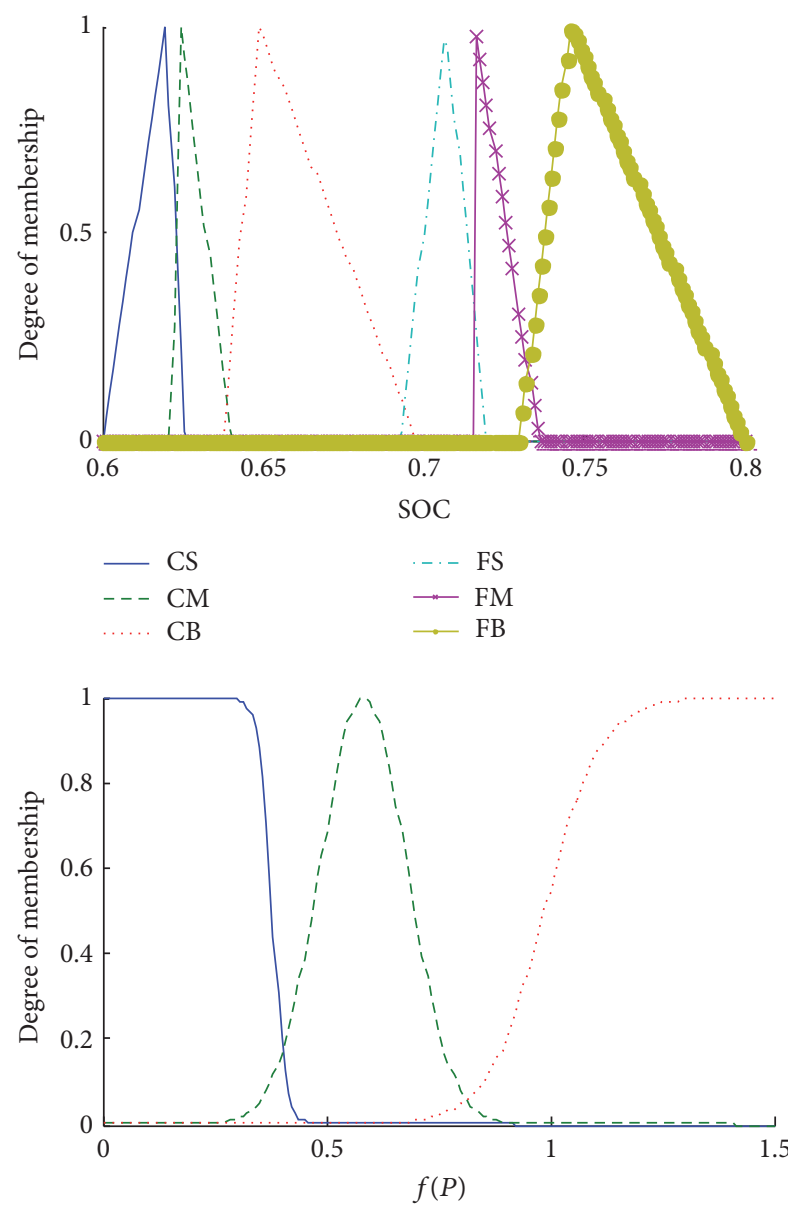

$$
\begin{array}{ll}
- & \mathrm{S} \\
--- & \mathrm{M} \\
\ldots \ldots & \mathrm{B}
\end{array}
$$

\begin{tabular}{lccccccc}
\multicolumn{8}{c}{ Output value of Sugeno } \\
\hline$x_{f}$ & VS & S & RS & M & RB & B & VB \\
\hline Value & 0.8 & 0.8291 & 0.8736 & 0.8804 & 0.9398 & 1.0912 & 1.2
\end{tabular}

FIGURE 18: Optimized membership functions.

and communicates (or rather outputs power management instructions) with dSPACE by USB CAN.

The hardware of HILS platform is shown in Figure 16. To obtain the driving states of vehicle, a monitor interface is built in monitor terminal based on Controldesk, which is shown in Figure 17 [30, 31].

Based on the platform introduced above, a $1600 \mathrm{~s}$ hardware-in-the-loop experiment is taken to verify the validity of system models and control strategy. After that, to obtain an optimum power management strategy, an optimization which uses same input conditions is carried out. Sampling time for all simulations is selected as $0.001 \mathrm{~s}$. Parameters of the tracked vehicle used for simulation are shown in Table 3.

The optimized membership functions of fuzzy controller and the results of HILS are shown in Figures 18 and 19, respectively. Figures 19(b) and 19(c) represent the signals of acceleration pedal and steering wheel, respectively. Figure 19(a) 


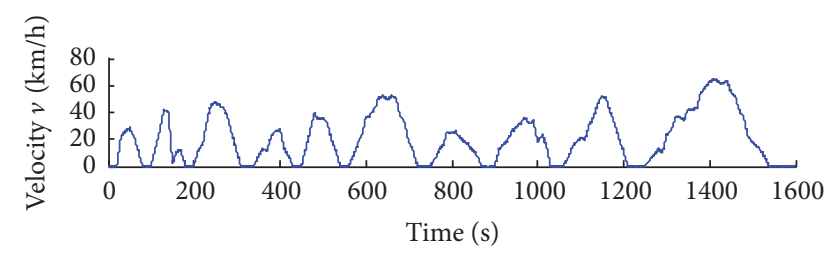

(a)

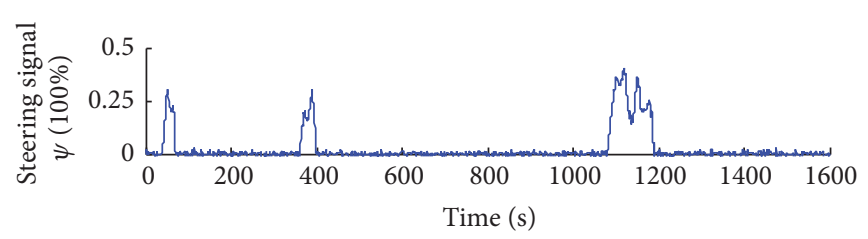

(c)

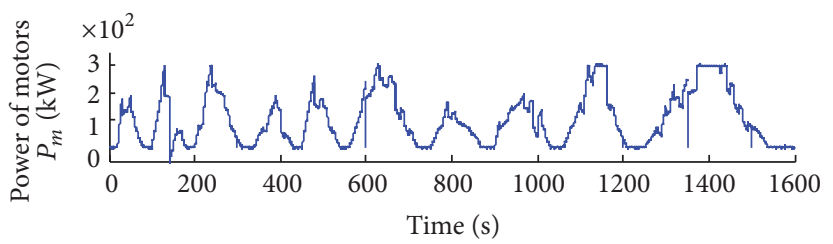

(e)

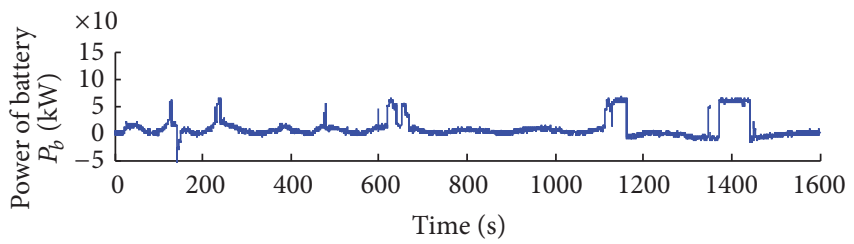

(g)

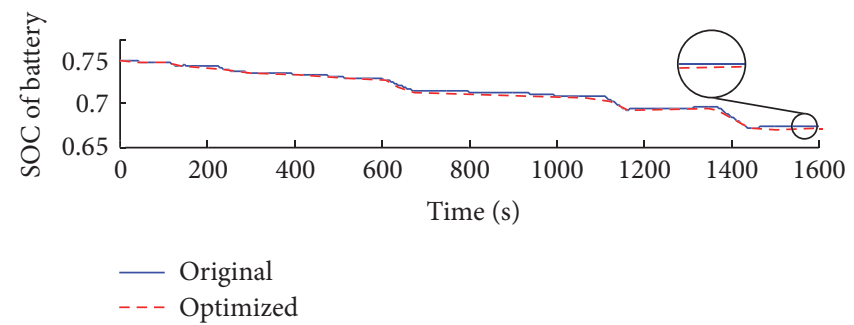

(i)

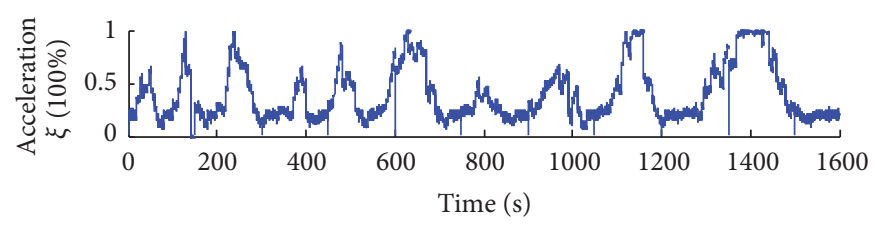

(b)

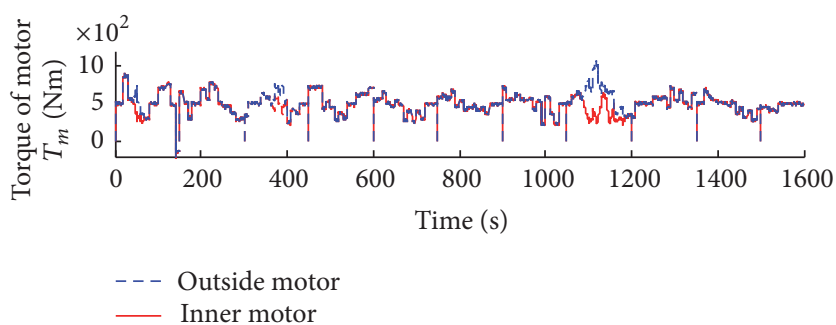

(d)

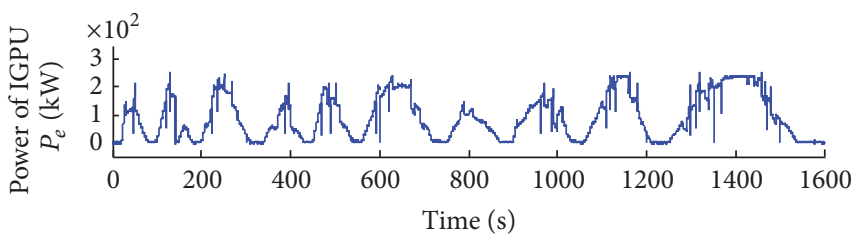

(f)

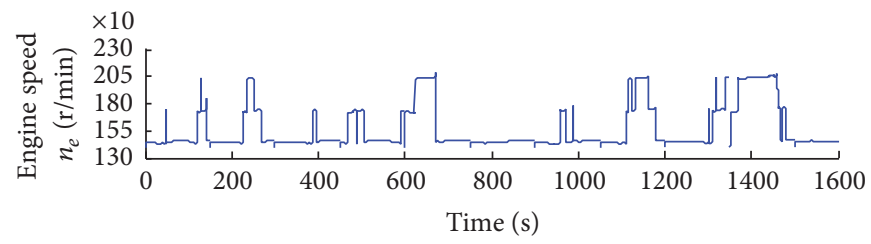

(h)

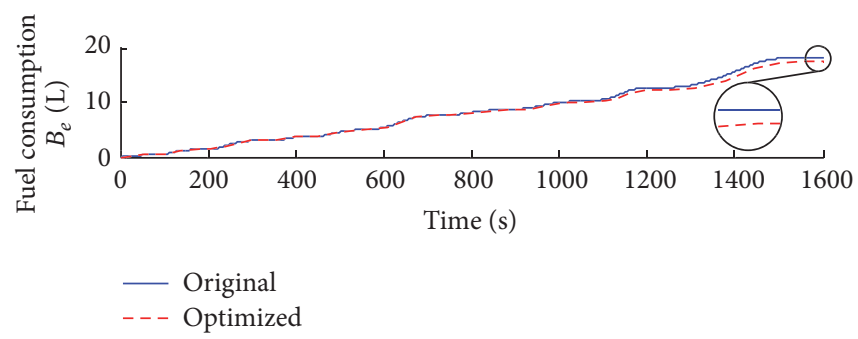

(j)

FIGURE 19: The results of HILS experiment.

represents the velocity of tracked vehicle, which is calculated according to the dynamic model and driver input signals. Figure 19(d) represents the torque of driving motors. From the figures we could find that steering of vehicle is achieved by torque difference between outside and inner motors, and the difference is increased by strengthening of steering intention. Figures 19(e), 19(f), and 19(g) are, respectively, the target power of driving motors, output power of IGPU, and output power of battery. It can be seen from the figures that strong and changeable load demand does not affect the efficient management of target power: when the load is low, target power is provided mostly by IGPU, which will reduce the working frequency of battery and prolong its service life. When the load is high, battery provides a timely power supplement to ensure the adequate satisfaction of target power and keep IGPU working in an economical area. In Figure 19(h) we could find that the value of engine operation speed correctly corresponds to the fixed speed point set in the economical area. Figures 19(i) and 19(j) represent the variance of SOC and consumption of fuel before and after optimization, respectively. After optimization, SOC of battery changed from 0.674 to 0.671 , decreased by $0.445 \%$, 


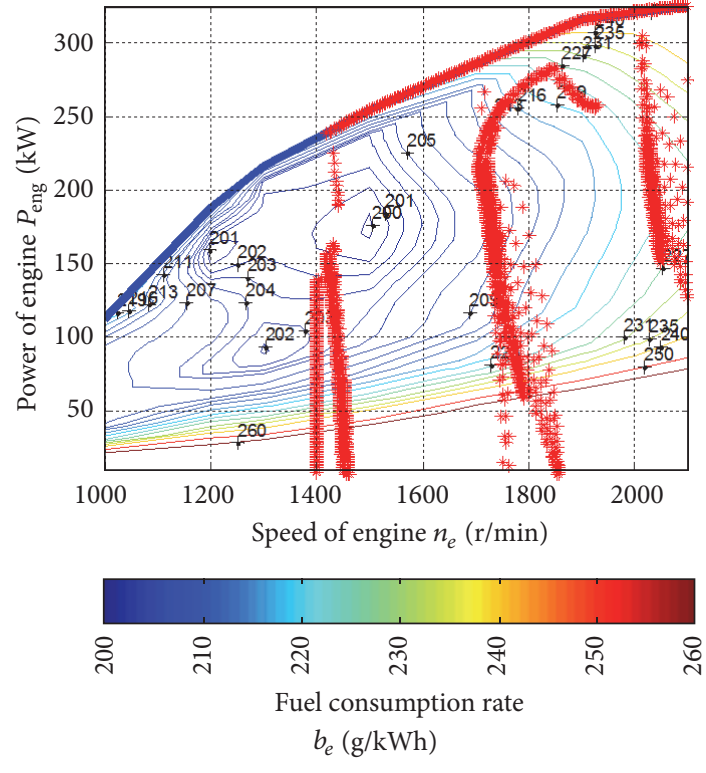

FIGURE 20: Engine operating points before optimization.

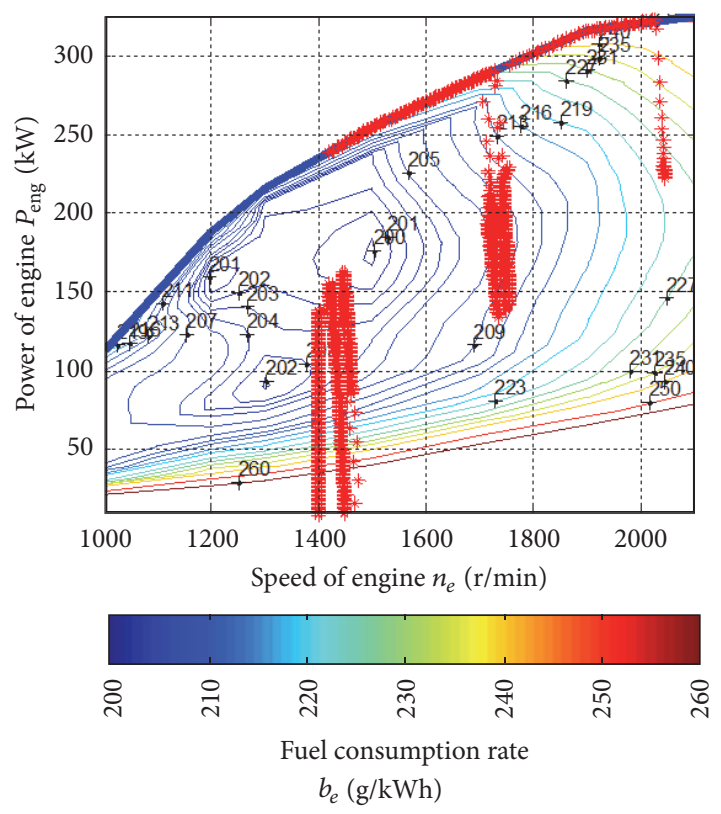

FIGURE 21: Engine operating points after optimization.

and the variance is within the interval set in (19). The fuel consumption after optimization changed from $18.346 \mathrm{~L}$ to $17.451 \mathrm{~L}$, decreased by $4.88 \%$.

Figures 20 and 21 show the engine operating points before and after optimization, respectively. From the figures we could find that, on the same input conditions, optimized electric drive system has much more economical operating points. The results of HILS experiment reveal that the proposed control strategy has excellent performance on power

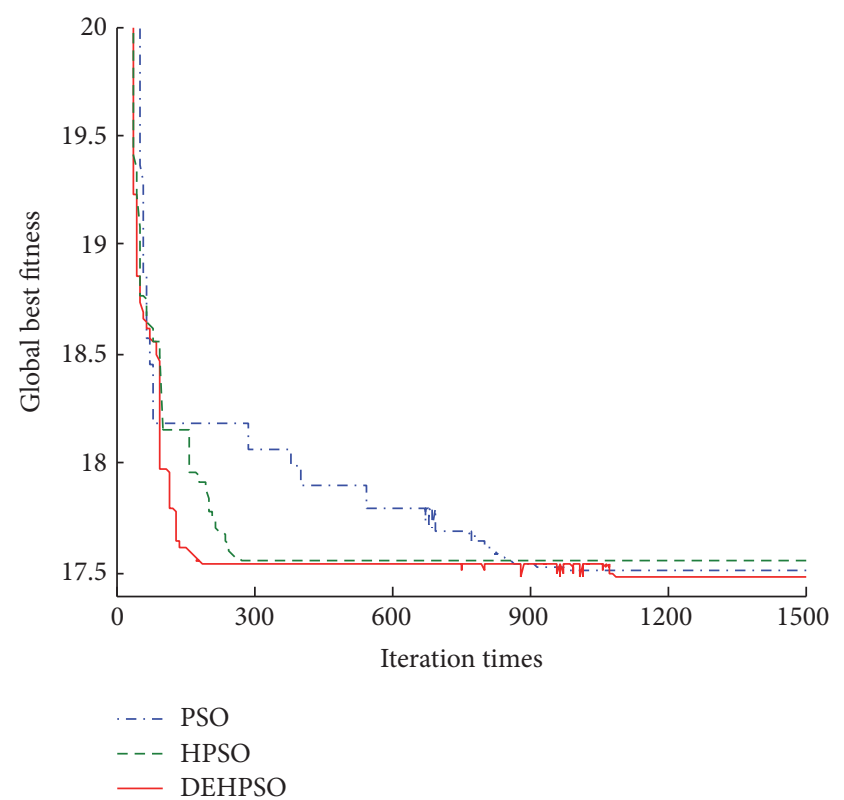

FIgURE 22: Optimization effects of different algorithms.

management of electric drive system, and the fuel economy has achieved a significant improvement by optimization of DEHPSO.

The optimization effects of different optimization algorithms are shown in Figure 22. From the figure we could know that PSO has a good optimization effect but the calculation speed is slow. HPSO takes shorter time but converges quickly. By contrast, DEHPSO takes the fitness value of 17.52 at iteration of 220, which achieves better optimization effect in a shorter calculation time. In later time of calculation (iteration: 700-1150), DEHPSO also has possibility to prevent premature convergence and obtains the best fitness; therefore, DEHPSO is more suitable to be used to optimize the power management control strategy.

\section{Conclusions}

This paper takes the power management control strategy of tracked vehicle electric drive system as study object; the simulation models of electric drive system are built based on theoretical analysis and experiment works. A novel power management control strategy based on fuzzy theory is proposed. In order to achieve a further improvement in fuel economic, a differential evolution based hybrid particle swarm optimization algorithm is adopted to optimize the fuzzy controller. To verify the validity of models and control strategy, a driver-controller HILS platform is built based on dSPACE and related experiments are carried out. The experiment result reveals that the optimized strategy has excellent performance in power management, fuel saving, and working efficiency, which provides an effective method for the design and application of power management control strategy of electric drive system. 
TABLE 4: Relationship between driving signals and target torque when steering.

\begin{tabular}{lcccc}
\hline & & Steering & \\
Steering condition & & Accelerate \& big radius & Accelerate \& small radius & Brake \\
& & $\xi \in[0,1]$ & $\xi \in[0,1]$ & $\xi \in[-1,0]$ \\
& & $\psi \in[0,1]$ & $\psi \in[-1,0]$ & $\xi \in[-1,1]$ \\
\hline \multirow{2}{*}{ Target torque } & $T_{2}^{*}$ & $\xi \psi T_{\max }\left(n_{1}\right)$ & $\xi \psi T_{\max }\left(n_{2}\right)$ & $\xi T_{\max }\left(n_{2}\right)$ \\
& $T_{1}^{*}$ & $\xi T_{\max }\left(n_{1}\right)$ & $\psi T_{\max }\left(n_{1}\right)$ & $\xi \psi T_{\max }\left(n_{1}\right)$ \\
\hline
\end{tabular}

TABLE 5: Relationship between driving signals and target torque when returning.

\begin{tabular}{lcccc}
\hline & & Returning & \\
& & Brake \& small radius & Brake \& big radius & Accelerate \\
Returning condition & $\xi \in[-1,0]$ & $\xi \in[-1,0]$ & $\xi \in[0,1]$ \\
& & $\psi \in[0,1]$ & $\psi \in[-1,0]$ & $\psi \in[-1,1]$ \\
\hline \multirow{2}{*}{ Target torque } & $T_{2}^{*}$ & $\xi \psi T_{\max }\left(n_{1}\right)$ & $\psi T_{\max }\left(n_{2}\right)$ & $\xi T_{\max }\left(n_{2}\right)$ \\
& $T_{1}^{*}$ & $\xi T_{\max }\left(n_{1}\right)$ & $\xi \psi T_{\max }\left(n_{1}\right)$ & $\xi \psi T_{\max }\left(n_{1}\right)$ \\
\hline
\end{tabular}

\section{Appendix}

Collected driving signals mainly include acceleration signal, braking signal, and steering signal. Acceleration/braking signal can be defined as follows:

$$
\xi=k_{\mathrm{sig}} \frac{\delta-\delta_{0}}{\delta_{\max }-\delta_{0}} \quad(-1 \leq \xi \leq 1),
$$

where $\delta$ is the instantaneous angular displacement of pedal and $\delta_{0}$ and $\delta_{\max }$ are the free stroke angular displacement and maximum angular displacement of pedal, which take the value of $5^{\circ}$ and $60^{\circ}$ in this paper, respectively. $k_{\text {sig }}$ is a sign function which takes the value of 1 when driving and -1 when braking.

Steering signal can be defined as follows:

$$
\psi= \begin{cases}\frac{\lambda-\lambda_{0}}{\lambda_{1}-\lambda_{0}} & \left(\lambda_{0}<\lambda \leq \lambda_{1}\right) \\ 1 & \left(0 \leq \lambda \leq \lambda_{0}\right) \\ \frac{\lambda_{1}-\lambda}{\lambda_{2}-\lambda_{1}} & \left(\lambda_{1}<\lambda \leq \lambda_{2}\right),\end{cases}
$$

where $\lambda$ is the instantaneous angular displacement of steering wheel and $\lambda_{0}, \lambda_{1}$, and $\lambda_{2}$ are the angular displacement of free stroke, double-motor driving, and single-motor driving, which take the value of $18^{\circ}, 90^{\circ}$, and $180^{\circ}$, respectively.

To obtain a rapid response to the driving intention when steering/returning, target torque of lateral motor $\left(T_{1}^{*}\right)$ should be larger than the torque of inner motor $\left(T_{2}^{*}\right)$, and response speed increases as the difference increases/decreases. The relationship between driving signals and target torque of motor when steering and returning is expressed in Tables 4 and 5 .

\section{Competing Interests}

The authors declare that there is no conflict of interests regarding the publication of this paper.

\section{Acknowledgments}

This work was supported by the National Key Research and Development Project of China (Project no. 2016YFC0802903).

\section{References}

[1] N. Jalil, N. A. Kheir, and M. Salman, "A rule-based energy management strategy for a series hybrid vehicle," in Proceedings of the American Control Conference, vol. 1, pp. 689-693, Albuquerque, NM, USA, June 1997.

[2] H. Banvait, S. Anwar, and Y. Chen, "A rule-based energy management strategy for Plug-in Hybrid Electric Vehicle (PHEV)," in Proceedings of the American Control Conference (ACC '09), pp. 3938-3943, IEEE, St. Louis, Mo, USA, June 2009.

[3] M. Montazeri-Gh, A. Ahmadi, and M. Asadi, "Driving condition recognition for genetic-fuzzy HEV control," in Proceedings of the 3rd International Workshop on Genetic and Evolving Fuzzy Systems, Witten-Bommerholz, Germany, March 2008.

[4] L. V. Perez, G. R. Bossio, D. Moitre, and G. O. García, "Optimization of power management in an hybrid electric vehicle using dynamic programming," Mathematics and Computers in Simulation, vol. 73, no. 1-4, pp. 244-254, 2006.

[5] G. Paganelli, S. Delprat, T. Guerra et al., "Equivalent consumption minimization strategy for parallel hybrid powertrain," in Proceedings of the IEEE 55th Vehicular Technology Conference (VTC '02), vol. 4, pp. 2076-2081, Birmingham, UK, May 2002.

[6] P. Rodatz, G. Paganelli, A. Sciarretta, and L. Guzzella, "Optimal power management of an experimental fuel cell/supercapacitor- powered hybrid vehicle," Control Engineering Practice, vol. 13, no. 1, pp. 41-53, 2005.

[7] C.-J. Xie, S.-H. Quan, and Q.-H. Chen, "Control strategy of hybrid power system for Fuel Cell Electric Vehicle based on neural network optimization," in Proceedings of the IEEE International Conference on Automation and Logistics (ICAL '08), pp. 753-757, Qingdao, China, September 2008.

[8] L. A. Zadeh, "Fuzzy sets," Information \& Control, vol. 8, no. 3, pp. 338-353, 1965.

[9] Y.-J. Liu and S. Tong, "Adaptive fuzzy control for a class of nonlinear discrete-time systems with backlash," IEEE Transactions on Fuzzy Systems, vol. 22, no. 5, pp. 1359-1365, 2014. 
[10] Y. Gao and Y.-J. Liu, "Adaptive fuzzy optimal control using direct heuristic dynamic programming for chaotic discretetime system," Journal of Vibration \& Control, vol. 22, no. 2, pp. 595-603, 2016.

[11] Y.-J. Liu, Y. Gao, S. Tong, and Y. Li, "Fuzzy approximation-based adaptive backstepping optimal control for a class of nonlinear discrete-time systems with dead-zone," IEEE Transactions on Fuzzy Systems, vol. 24, no. 1, pp. 16-28, 2016.

[12] G. Y. Lai, Z. Liu, Y. Zhang, C. L. P. Chen, S. L. Xie, and Y. J. Liu, "Fuzzy adaptive inverse compensation method to tracking control of uncertain nonlinear systems with generalized actuator dead zone," IEEE Transactions on Fuzzy Systems, 2016.

[13] B. Chen, C. Lin, X. Liu, and K. Liu, "Observer-based adaptive fuzzy control for a class of nonlinear delayed systems," IEEE Transactions on Systems, Man, and Cybernetics: Systems, vol. 46, no. 1, pp. 27-36, 2016.

[14] S.-C. Tong, L.-L. Zhang, and Y.-M. Li, "Observed-based adaptive fuzzy decentralized tracking control for switched uncertain nonlinear large-scale systems with dead zones," IEEE Transactions on Systems, Man, and Cybernetics: Systems, vol. 46, no. 1, pp. 37-47, 2016.

[15] C. L. P. Chen, Y.-J. Liu, and G.-X. Wen, "Fuzzy neural networkbased adaptive control for a class of uncertain nonlinear stochastic systems," IEEE Transactions on Cybernetics, vol. 44, no. 5, pp. 583-593, 2014.

[16] G.-X. Wen, C. L. P. Chen, Y.-J. Liu, and Z. Liu, "Neural-networkbased adaptive leader-following consensus control for secondorder non-linear multi-agent systems," IET Control Theory and Applications, vol. 9, no. 13, pp. 1927-1934, 2015.

[17] Y. J. Liu, S. C. Tong, C. L. Chen, and D. J. Li, "Neural controller design-based adaptive control for nonlinear MIMO systems with unknown hysteresis inputs," IEEE Transactions on Cybernetics, vol. 46, no. 1, pp. 9-19, 2016.

[18] M. H. Hajimiri and F. R. Salmasi, "A fuzzy energy management strategy for series hybrid electric vehicle with predictive control and durability extension of the battery," in Proceedings of the IEEE Conference on Electric and Hybrid Vehicles (ICEHV '06), pp. 1-5, IEEE, Pune, India, December 2006.

[19] N. J. Schouten, M. A. Salman, and N. A. Kheir, "Energy management strategies for parallel hybrid vehicles using fuzzy logic," Control Engineering Practice, vol. 11, no. 2, pp. 171-177, 2003.

[20] N. J. Schouten, M. A. Salman, and N. A. Kheir, "Fuzzy logic control for parallel hybrid vehicles," IEEE Transactions on Control Systems Technology, vol. 10, no. 3, pp. 460-468, 2002.

[21] C.-Y. Li and G.-P. Liu, "Optimal fuzzy power control and management of fuel cell/battery hybrid vehicles," Journal of Power Sources, vol. 192, no. 2, pp. 525-533, 2009.

[22] J. M. Liu, Modeling Configuration and Control Optimization of Power-Split Hybrid Vehicles, University of Michigan, Detroit, Mich, USA, 2007.

[23] A. Sciarretta and L. Guzzella, "Control of hybrid electric vehicles," IEEE Control Systems Magazine, vol. 27, no. 2, pp. $60-$ 70, 2007.

[24] M. Pan, J. Yan, Q. Tu, and C. Jiang, "Research on the multienergy management strategy of the electric drive system of a tracked bulldozer," Mathematical Problems in Engineering, vol. 2016, Article ID 5631209, 13 pages, 2016.

[25] H.-W. He, R. Xiong, H.-Q. Guo, and S.-C. Li, "Comparison study on the battery models used for the energy management of batteries in electric vehicles," Energy Conversion and Management, vol. 64, pp. 113-121, 2012.
[26] W. Waag, Ch. Fleischer, and D. U. Sauer, "On-line estimation of lithium-ion battery impedance parameters using a novel variedparameters approach," Journal of Power Sources, vol. 237, pp. 260-269, 2013.

[27] K. E. Parsopoulos and M. N. Vrahatis, "Unified particle swarm optimization in dynamic environments," in Applications of Evolutionary Computing, F. Rothlauf, J. Branke, S. Cagnoni et al., Eds., vol. 3449 of Lecture Notes in Computer Science, pp. 590599, Springer, Berlin, Germany, 2005.

[28] G. T. Pulido, A. Coello, and C. Coello, "Using clustering techniques to improve the performance of a multi-objective particle swarm optimizer," in Genetic and Evolutionary ComputationGECCO 2004: Genetic and Evolutionary Computation Conference, Seattle, WA, USA, June 26-30, 2004. Proceedings, Part I, vol. 3102 of Lecture Notes in Computer Science, pp. 225-237, Springer, Berlin, Germany, 2004.

[29] M. Pan, J. Yan, Q. Tu, and C. Jiang, "Fuzzy control and wavelet transform-based energy management strategy design of a hybrid tracked bulldozer," Journal of Intelligent and Fuzzy Systems, vol. 29, no. 6, pp. 2565-2574, 2015.

[30] dSPACE, DS1104 R\&D Controller Board, Installation and Configuration Guide, dSPACE GmbH, Paderborn, Germany, 2001.

[31] dSPACE, Real Time Interface (RTI and RTI-MP) Implementation Guide, dSPACE GmbH, Paderborn, Germany, 2001. 


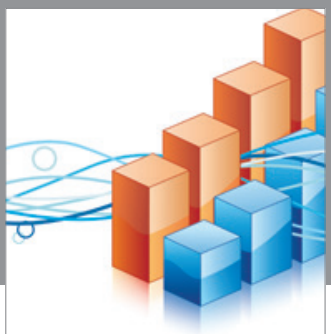

Advances in

Operations Research

vatem alat4

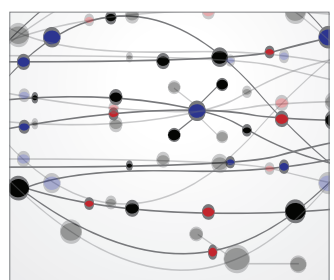

\section{The Scientific} World Journal
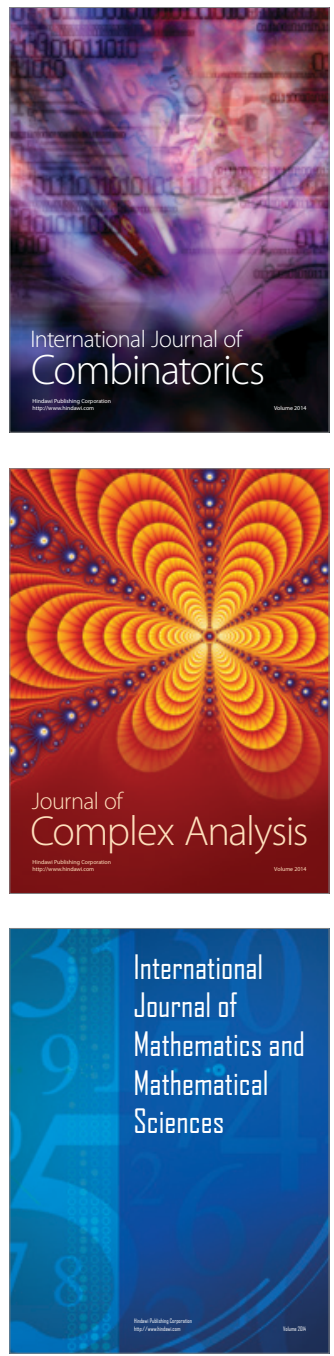
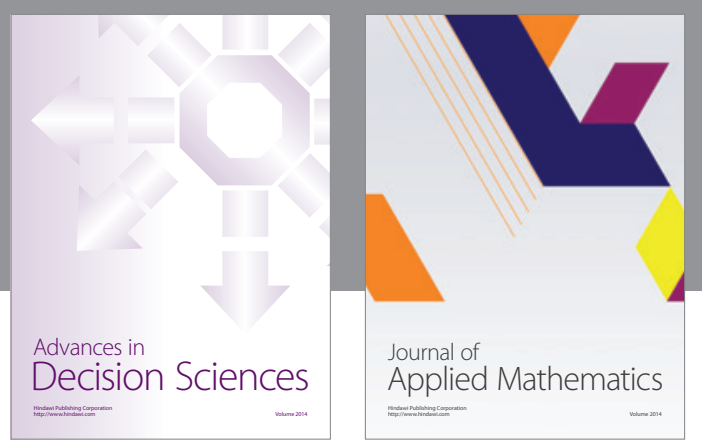

Algebra

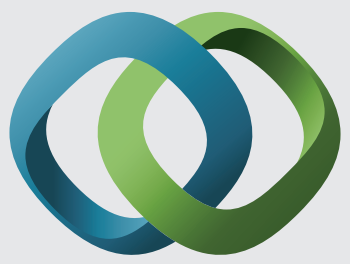

\section{Hindawi}

Submit your manuscripts at

http://www.hindawi.com
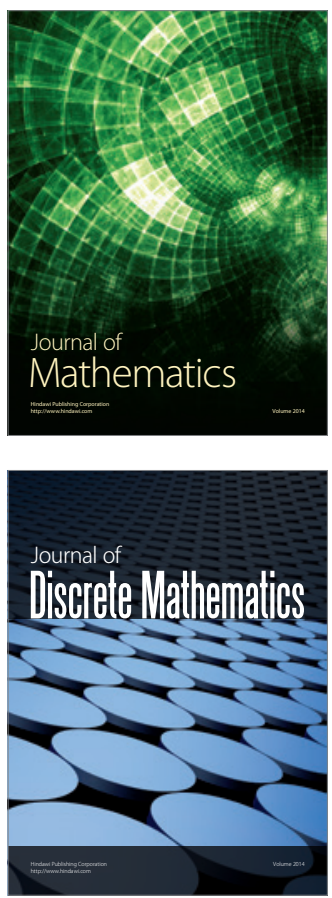

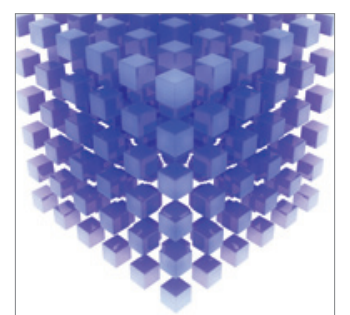

Mathematical Problems in Engineering
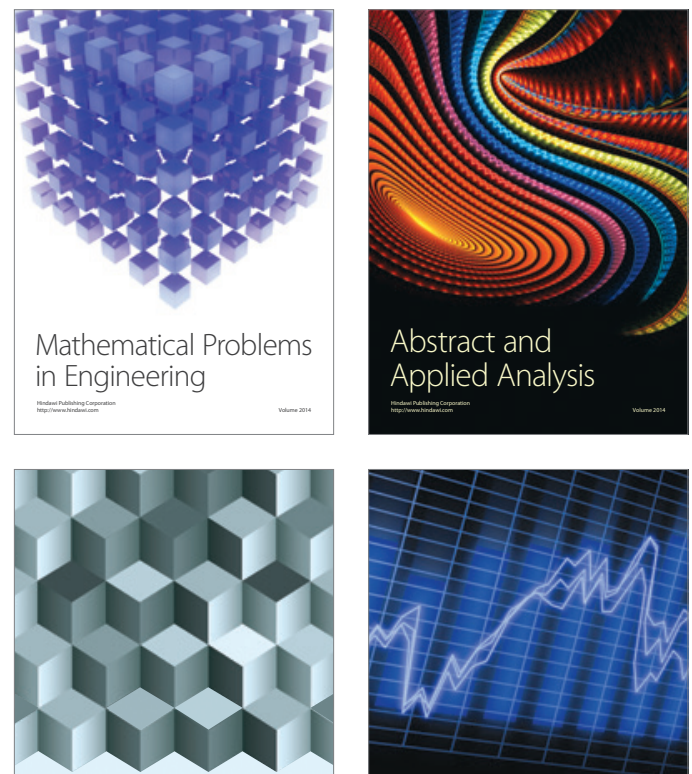

Journal of

Function Spaces

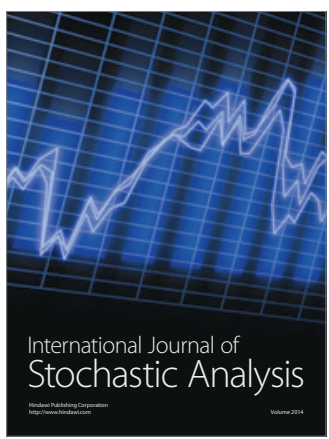

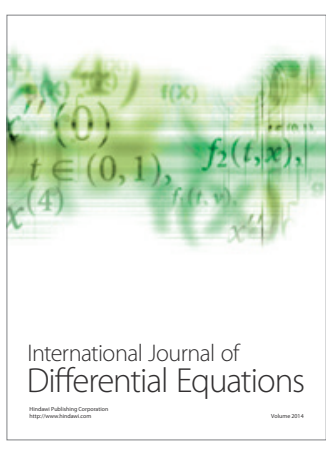
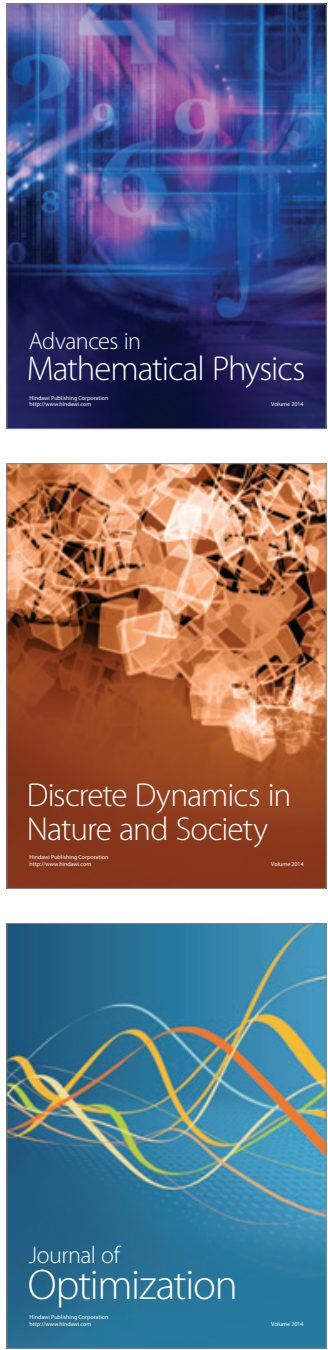